\title{
PENGARUH MODAL DAN PERMINTAAN TERHADAP PENDAPATAN PEDAGANG IKAN TONGKOL LISONG DIKOTA LHOKSEUMAWE
}

\author{
Hijri Juliansyah ${ }^{\mathrm{a}^{*}}$, Saraturrahmi $^{\mathrm{a}^{*}}$ \\ ${ }^{a}$ Fakultas Ekonomi dan Bisnis Universitas Malikussaleh \\ *Corresponding author: hijri.juliansyah@ gmail.com
}

\begin{tabular}{lll}
\hline ARTICLE INFORMATION ABSTRACT \\
\hline
\end{tabular}

Keywords:

Capital, Demand and Income
This study aims to see the influence of theCapital and Demand for income of lisong tuna fish retailers in the city of Lhokseumawe. The data used in this study are primary data obtained from the survey for 60 respondents. The data analysis used in this study is a Multiple Linear Regression Model. The Results that simultaneously capital and demand positive and significant effect on the income of lisong tuna fish traders in the city of Lhokseumawe. Partially the price of demand is significant and has a positive effect, while capital is not significant.

\section{PENDAHULUAN}

Ikan tongkol lisong (auxis rochei) merupakan ikan laut yang termasuk pada jenis ikan pelagis kecil dan mempunyai daerah penyebaran yang luas umumnya mendiami perairan neritik. Ikan tongkol lisong dalam bahasa aceh disebut jereubok yang terdapat di seluruh perairan termasuk laut kepulauan dan laut nusantara. Bagi masyarakat Kota Lhokseumawe, ikan tongkol lisong merupakan ikan komoditas utama yang benilai ekonomis tinggi. Ikan tongkol lisong merupakan hasil penangkapan dengan menggunakan jaring hanyut. Kenaikan yang pesat dari harga dan produksi menunjukkan bahwa penangkapan ikan tongkol lisong merupakan usaha yang prospektif. Permintaan ikan tongkol lisong yang tinggi menjadikan ikan tersebut lebih banyak diminati dari pada ikan pelagis lainnya sehingga menjadi target penangkapan utama bagi para nelayan.

Modal yang dimiliki oleh pedagang relatif masih rendah karena modal tersebut bersumber dari aset pribadi pedagang. Permintaan terhadap ikan tongkol lisong yang tidak menentu mengakibatkan pendapatan yang diperoleh pedagang belum tentu cukup untuk modal membeli stok ikan tongkol lisong selanjutnya.
Berdasarkan penelitian terdahulu yang dilakukan Sumardianto, Yulinda, dan Bathara (2016). Faktor Yang Mempengaruhi Pendapatan Pedagang Pengecer Ikan Laut Segar Di Pasar Terapung Tembilahan Kabupaten Indragiri Hilir Provinsi Riau. Metode yang digunakan dalam penelitian ini adalah metode survey dengan jumlah responden sebanyak 13 orang. Tingkat pendapatan yang diterima pedagang pengecer ikan laut segar di Pasar Terapung Kota Tembilahan tergolong tinggi yaitu antara Rp 59.970.000,- sampai Rp 88.650.000,- per bulan untuk pendapatan kotor dan Rp 1.717.500,- sampai Rp 5.377.500,- per bulan untuk pendapatan bersih. Proporsi pengaruh variabel modal, jumlah ikan dan lama berusaha secara simultan terhadap pendapatan pedagang pengecer ikan laut di Pasar Terapung sebesar 96,9\%. Modal memberikan pengaruh yang signifikan terhadap pendapatan pedagang pengecer dengan nilai koefisien regresi sebesar 1,460. Sedangkan, jumlah ikan dan lama berusaha tidak berpengaruh signifikan terhadap pendapatan pedagang pengecer dengan nilai koefisien regresi masing-masing sebesar 0,478 dan 0,026.

Penelitian di atas memiliki persamaan dengan penelitian ini yaitu sama-sama menggunakan metode survey. Sedangkan 
perbedaannya terletak pada lokasi penelitiannya.Dengan melihat latar belakang diatas maka dapat diambil rumusan masalahnya yaitu "Pengaruh Modal dan perrmintaan terhadap pendapatan pedagang ikan tongkol lisong di Kota Lhokseumawe".

\section{LANDASAN TEORITIS}

\section{Pengertian Pendapatan}

Menurut Patty dan Rita (2015) pendapatan adalah penerimaan seseorang dalam bentuk uang tunai atau bukan tunai yang diperoleh ketika terjadi transaksi antara pedagang dan pembeli dalam suatu kesepakatan bersama.

\section{Pengertian Modal}

Selain itu Modal juga merupakan dana yang dipergunakan untuk membeli barang dagangan, pembiayaan operasional dan pembiayaan upah lainnya yang berlangsung terus-menerus selama kegiatan jual beli yang diharapkan akan meningkatkan pendapatan pedagang. Sehingga definisi modal dalam penelitian ini adalah sejumlah dana yang digunakan oleh pedagang ikan tongkol untuk membiayai proses pendirian usaha dan pembiayaan kegiatan operasional sehari-hari.

\section{Kaitan Modal terhadap Pendapatan}

Modal merupakan input (faktor produksi) yang sangat penting dalam menentukan tinggi rendahnya pendapatan. Tetapi bukan berarti merupakan faktor satu-satunya yang dapat meningkatkan pendapatan. Semakin banyak modal yang dikeluarkan maka akan semakin tinggi pendapatan yang diperoleh.

\section{Pengertian Permintaan}

Menurut Sukirno (2013) sejumlah penentu dan total permintaan dipengaruhi oleh beberapa faktor, antara lain:

a. Harga barang itu sendiri

Jika harga barang itu meningkat maka permintaan terhadap barang tersebut akan menurun. Jika harga barang itu menurun maka permintaan terhadap barang tersebut akan meningkat.

b. Harga barang lain dibagi menjadi dua bagian yaitu:
1. Barang substitusi (pengganti)

Jika konsumen dapat menggunakan salah satu jenis barang untuk memenuhi fungsi yang sama pada dua barang tersebut, jika harga satu unit barang $X$ meningkat, maka permintaan barang $X$ menurun. Namun permintaan terhadap barang $\mathrm{Y}$ akan meningkat.

2. Barang komplementer (pelengkap)

Jika harga barang $\mathrm{X}$ meningkat maka akan menyebabkan permintaan barang $\mathrm{Y}$ menurun.

\section{Pendapatan penduduk}

Permintaan merupakan keinginan konsumen dan kemampuan untuk membayar suatu barang. Penghasilan merupakan faktor utama dan kemampuan untuk membayar konsumen. Untuk sebagian barang-barang, ketika penghasilan meningkat permintaan barang juga akan meningkat. Dengan demikian untuk barang-barang normal, peningkatan hasil pendapatan ditandai dengan bergesernya ke arah kanan dari kurva permintaan. Sedangkan barang-barang inferior, memiliki level hasil penghasilan yang tinggi akan ditandai dengan bergesernya ke arah kiri dari kurva permintaan.

\section{Hubungan Permintaan terhadap Pendapatan}

Hubungan antara permintaan dengan pendapatan yaitu ketika permintaan terhadap suatu barang menurun maka pendapatan yang diterima oleh pedagang akan menurun. Sebaliknya ketika permintaan terhadap suatu barang meningkat maka pendapatan yang diterima pedagang akan meningkat.

\section{Cita rasa}

Cita rasa atau selera yaitu semakin tinggi cita rasa terhadap suatu barang maka permintaan terhadap suatu barang akan meningkat.

\section{Jumlah penduduk}

Peningkatan jumlah penduduk akan meningkatkan permintaan untuk barang dengan mengasumsikan faktor lain konstan. 


\section{METODE PENELITIAN}

Jenis data yang digunakan dalam penelititan skripsi ini adalah data primer yang diolah secara kuantitatif. Adapun sumber data dalam penelitian ini menggunakan data primer yang diperoleh dengan cara survei dan wawancara dengan menggunakan kuisioner kepada pedagang ikan tongkol di pasar Kota Lhokseumawe. Populasi dalam penelitian ini adalah seluruh pedagang ikan tongkol lisong yang ada di Pasar Pusong, Pasar Impres, Pasar Cunda, Pasar Punteut dan Pasar Bathupat yaitu sebesar 60 orang. Menurut Sugiyono (2015:83), Sampel adalah bagian dari jumlah dan karakteristik yang dimiliki oleh populasi. Adapun sampel dalam penelitian ini berjumlah 60 orang Pedagang Ikan Tongkol Lisong di Kota Lhokseumawe yang diambil berdasarkan teknik penarikan sampel yang menggunakan metode sensus karna sensus populasi dijadikan sampel. Untuk menganalisis pengaruh modal dan permintaan terhadap pendapatan pedagang ikan tongkol lisong di kota Lhokseumawe maka pengolahan data dilakukan dengan metode analisis regresi linier berganda. Uji asumsi klasik yang digunakan dalam penelitian ini adalah uji normalitas, uji multikolinearitas dan uji heteroskedastisitas. Untuk menjawab hipotesis dan selanjutnya mengetahui tingkat signifikan dari masing-masing variabel maka digunakan uji hipotesis yaitu uji t dan uji F. Untuk mengetahui pengaruh dan hubungan korelasi antar variabel maka dapat dilihat dari koefisien determinasi dan koefisien korelasi.

\section{HASIL PENELITIAN}

\section{Hasil Regresi}

Tabel 1.

Hasil Regresi Pengaruh Modal dan Permintaan Terhadap Pendapatan Pedagang Ikan Tongkol Lisong Di Kota Lhokseumawe

\section{Dependent Variable: $Y$}

Method: Least Squares

Date: $03 / 02 / 18 \quad$ Time:

$14: 15$
Included observations: 60

\begin{tabular}{|c|c|c|c|}
\hline \multirow[b]{2}{*}{ Variable } & \multicolumn{2}{|r|}{$\begin{array}{l}\text { Std. } \\
\text { Erro }\end{array}$} & \multirow[b]{2}{*}{ Prob. } \\
\hline & Coefficient & $r \quad t$-Statistic & \\
\hline & & $\begin{array}{l}235 \\
87.9\end{array}$ & \\
\hline C & -22532.51 & $\begin{array}{l}7 \\
0.02 \\
881\end{array}$ & 0.3435 \\
\hline X1 & 0.038304 & $\begin{array}{ll}8 & 1.329192 \\
839 . & \\
835 & \end{array}$ & 0.1891 \\
\hline $\mathrm{X} 2$ & 9014.122 & 210.73320 & 0.0000 \\
\hline R-squared & 0.821507 & $\begin{array}{l}\text { Mean } \\
\text { dependent var }\end{array}$ & 306666.7 \\
\hline $\begin{array}{l}\text { Adjusted } \\
\text { R-squared }\end{array}$ & 0.815245 & $\begin{array}{l}\text { S.D. } \\
\text { dependent var }\end{array}$ & 201537.9 \\
\hline $\begin{array}{l}\text { S.E. O } \\
\text { regression } \\
\text { Sum }\end{array}$ & 86627.40 & iterion & 25.62533 \\
\hline $\begin{array}{l}\text { squared } \\
\text { resid }\end{array}$ & $4.28 \mathrm{E}+11$ & $\begin{array}{l}\text { Schwarz } \\
\text { criterion }\end{array}$ & 25.73004 \\
\hline $\begin{array}{l}\text { Log } \\
\text { likelihood }\end{array}$ & -765.7598 & $\begin{array}{l}\text { Hannan-Quinr } \\
\text { criter. }\end{array}$ & 25.66629 \\
\hline $\begin{array}{l}\text { F- } \\
\text { statistiגגג } \\
\text { Prob(F- } \\
\text { statistic) }\end{array}$ & $\begin{array}{l}131.1706 \\
0.000000\end{array}$ & $\begin{array}{c}\text { Durbin- } \\
\text { Watson stat }\end{array}$ & 1.299764 \\
\hline
\end{tabular}

Sumber : Hasil penelitian, 2018.

Dari hasil regresi diatas menunjukkan nilai konstanta adalah sebesar -22.532,51 yang berarti bahwa, apabila modal dan permintaan dianggap konstan maka pendapatan pedagang ikan tongkol lisong adalah sebesar -22.532,51 rupiah. Maksudnya, tanpa modal dan permintaan maka pendapatan pedagang ikan tongkol lisong adalah minus 22.532,51 rupiah. Nilai koefisien regresi dari modal adalah sebesar 0.038304 yang berarti bahwa, apabila modal meningkat sebesar 1 rupiah maka pendapatan pedagang ikan tongkol lisong akan meningkat sebesar 0.038304 rupiah. Nilai koefisien regresi dari permintaan adalah sebesar 9.014,122 yang berarti bahwa, apabila permintaan meningkat sebesar 1 kilogram maka pendapatan 
pedagang ikan tongkol lisong juga akan meningkat sebesar 9.014,122 rupiah.

\section{Uji Normalitas}

Penelitian ini menggunakan metode JarqueBera Test. Untuk melihat suatu data sudah berdistribusi normal atau tidak maka dapat membandingkan nilai J-B hitung dengan nilai $\lambda^{2}$ (chi-square) tabel. Apabila J-B hitung $>\lambda^{2}$ tabel maka residual data dalam model tersebut tidak berdistribusi normal. Apabila nilai J-B hitung $<^{2}$ tabel maka residual data dalam model tersebut sudah berdistribusi normal.

\section{Gambar 1. Uji Normalitas}

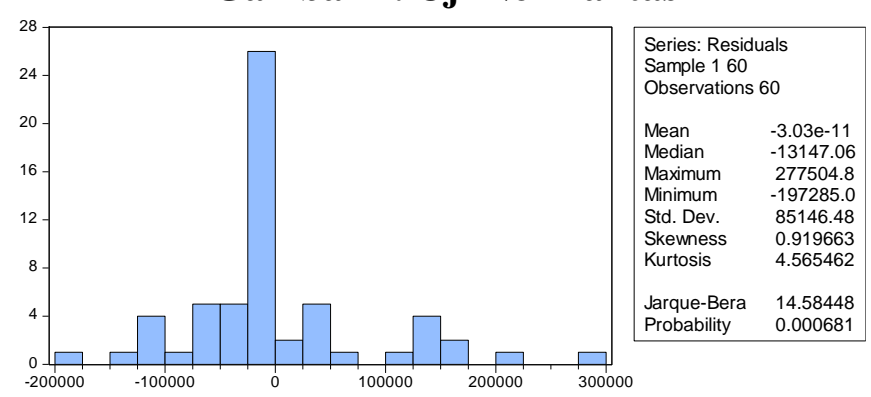

Sumber : Hasil Penelitian, 2018

Dari gambar diatas nilai jarque-bera adalah sebesar 14.58448 dan nilai $\lambda^{2}$ tabel dengan $\mathrm{df}=\mathrm{n}-$ $\mathrm{k}=57$ sebesar 75.62375. Dapat disimpulkan bahwa data dalam model tersebut memenuhi asumsi klasik normalitas. Hal ini juga dapat dilihat dari nilai jarque-bera hitung < nilai $\lambda^{2}$ tabel yaitu $14.58448<75.62375$ maka residual data dalam model ini sudah berdistribusi normal.

\section{Uji Multikolinearitas}

Tabel 2. Uji Multikolinearitas

\begin{tabular}{|l|l|l|}
\hline & $\mathrm{X} 1$ & $\mathrm{X} 2$ \\
\hline $\mathrm{X} 1$ & 1.000 .000 & 0.692006 \\
\hline $\mathrm{X} 2$ & 0.692006 & 1.000 .000 \\
\hline
\end{tabular}

Sumber : Hasil Penelitian, 2018.

Berdasarkan tabel 2 di atas dapat dilihat bahwa hubungan antara variabel modal dan permintaan tidak ada indikasi multikolinearitas karena nilai matrik korelasi antar masing-masing variabel bebas adalah $0.692006<0.80$.

\section{Uji Heteroskedastisitas}

Pengujian ini dapat dilakukan dengan menggunakan uji arch test yang tersedia dalam program eviews 9. Cara untuk mendeteksi ada atau tidak heteroskedastisitas yaitu dengan membandingkan nilai $\lambda^{2}$ dengan Obs*R-Square. Apabila nilai $\lambda^{2}$ lebih besar dari hasil Obs*RSquare maka tidak terjadi heteroskedatisitas. Apabila nilai $\lambda^{2}$ lebih kecil dari hasil Obs*RSquare maka terjadi heteroskedatisitas.

\section{Tabel 3. Uji heteroskedastisitas} Heteroskedasticity Test: ARCH

\begin{tabular}{llcc}
\hline \hline & 1.9068 & Prob. & 0.172 \\
F-statistic & 42 & $F(1,57)$ & 7 \\
& 1.9098 & Prob. & Chi-0.167 \\
Obs*R-squared 58 & Square(1) & 0 \\
\hline \hline
\end{tabular}

Sumber : Hasil Penelitian, 2018.

Berdasarkan tabel 3 dapat dilihat bahwa nilai $\mathrm{X}^{2}$ tabel dengan $\mathrm{df}=\mathrm{n}-\mathrm{k}=57$ sebesar 75.62375 dan nilai Obs*R-Square adalah sebesar 1.909858. Dapat disimpulkan nilai $\lambda^{2}$ tabel > Obs*R-Square yaitu $75.62375>1.909858$ yang berarti bahwa pada penelitian ini tidak terjadi heteroskedastisitas antara variabel modal dan permintaan terhadap pendapatan pedagang ikan tongkol lisong di Kota Lhokseumawe.

\section{Pembuktian Hipotesis}

\section{Uji Parsial (t)}

Dari hasil pengujian pada tabel 1 diatas menunjukkan bahwa variabel modal memiliki $t_{\text {hitung }}$ sebesar 1.329192 dengan nilai probabilitas statistiknya sebesar 0.1891 dan nilai $t_{\text {tabel }}$ dengan $\mathrm{df}=\mathrm{n}-\mathrm{k}=60-3=57$ pada $\alpha=0.10$ diperoleh nilai sebesar 1.29658. Dapat disimpulkan bahwa $t_{\text {hitung }}>t_{\text {tabel }}$ yaitu $1.329192>1.29658$ maka $\mathrm{H}_{01}$ ditolak dan $\mathrm{H}_{\mathrm{a} 1}$ diterima yang berarti bahwa modal berpengaruh secara positif namun tidak signifikan terhadap pendapatan pedagang ikan tongkol lisong. Hal ini juga bisa dilihat dari probabilitas hitung (p-value) sebesar $0.1891>$ 0.10 .

Variabel permintaan memiliki $t_{\text {hitung }}$ sebesar 10.73320 dengan nilai probabilitas statistiknya sebesar 0.0000 dan nilai $\mathrm{t}_{\text {tabel }}$ dengan $\mathrm{df}=\mathrm{n}-\mathrm{k}=$ $60-3=57$ pada $\alpha=0.05$ diperoleh nilai sebesar 1.67203. Dapat disimpulkan bahwa $t_{\text {hitung }}>t_{\text {tabel }}$ 
yaitu $10.73320>1.67203$ maka $\mathrm{H}_{02}$ ditolak dan $\mathrm{H}_{\mathrm{a} 2}$ diterima yang berarti bahwa permintaan berpengaruh secara positif dan signifikan terhadap pendapatan pedagang ikan tongkol lisong. Hal ini juga bisa dilihat dari probabilitas hitung ( $\mathrm{p}$-value) sebesar $0.0000<0.05$.

\section{Uji Simultan (F)}

Dari hasil pengujian pada tabel 1 menunjukkan bahwa variabel modal dan permintaan terhadap pendapatan pedagang ikan tongkol lisong memiliki $\mathrm{F}_{\text {hitung }}$ sebesar 131.1706 dengan probabilitas statistiknya sebesar 0.000000 dan nilai $\mathrm{F}_{\text {tabel }}$ dengan $\mathrm{df}=(\mathrm{k}-1)(\mathrm{n}-\mathrm{k})=(3-$ 1) $(60-3)=(2)(57)$ diperoleh nilai sebesar 3.16. Dapat disimpulkan bahwa $F_{\text {hitung }}>F_{\text {tabel }}$ yaitu $131.1706>3.16$ maka $\mathrm{H}_{0}$ ditolak dan $\mathrm{H}_{\mathrm{a}}$ diterima yang berarti bahwa secara bersama-sama variabel modal $\left(\mathrm{X}_{1}\right)$ dan permintaan $\left(\mathrm{X}_{2}\right)$ terhadap pendapatan pedagang ikan tongkol lisong (Y) berpengaruh secara signifikan dan positif. Hal ini juga bisa dilihat dari probabilitas hitung ( $p$-value) sebesar $0.000000<0.05$.

\section{Koefisien Determinasi $\left(\mathbf{R}^{2}\right)$ dan Koefisien Korelasi (R)}

\section{Koefisien Determinasi $\left(\mathbf{R}^{\mathbf{2}}\right)$}

Dari hasil pengujian pada tabel 1 diperoleh nilai $\mathrm{R}^{2}$ sebesar 0.815245 yang berarti bahwa pengaruh dari variabel modal dan permintaan terhadap pendapatan pedagang ikan tongkol lisong yaitu sebesar 0.815245 atau 81.5245 persen, sedangkan yang dipengaruhi oleh variabel lain diluar model ini adalah sebesar 0.184755 atau 18.4755 persen.

\section{Koefisien Korelasi (R)}

Untuk mengetahui hubungan antara variabel modal dan permintaan terhadap pendapatan pedagang ikan tongkol lisong dapat dilihat dari $\sqrt{\mathrm{R}^{2}}$. Dari hasil pengujian diperoleh $\sqrt{\mathrm{R}^{2}}=\sqrt{0.815245}=0.902909$ yang berarti bahwa hubungan antara modal $\left(\mathrm{X}_{1}\right)$ dan permintaan $\left(\mathrm{X}_{2}\right)$ terhadap pendapatan $(\mathrm{Y})$ pedagang ikan tongkol lisong berhubungan sangat erat secara positif karena nilai 0.902909 atau 90.2909 persen mendekati positif 1 .

\section{Pembahasan}

Penelitian penulis menyimpulkan bahwa secara parsial modal mempunyai pengaruh secara positif tetapi tidak signifikan terhadap pendapatan pedagang, karena jumlah modal yang dikeluarkan belum mampu untuk meningkatkan pendapatan. Sedangkan permintaan berpengaruh positif dan signifikan terhadap pendapatan. Secara simultan modal dan permintaan berpengaruh positif terhadap pendapatan pedagang ikan tongkol lisong, jika modal meningkat maka pendapatan pedagang ikan tongkol lisong akan meningkat. Namun bukan hanya modal yang menentukan tingginya pendapatan, karena ketika jumlah permintaan menurun maka pendapatan pedagang ikan tongkol lisong juga akan menurun.

\section{PENUTUP}

\section{Kesimpulan}

Berdasarkan dari hasil penelitian ini dapat diambil beberapa kesimpulan yaitu sebagai berikut:

1. Secara parsial (uji t) variabel modal berpengaruh secara positif tetapi tidak signifikan terhadap pendapatan pedagang ikan tongkol lisong di Kota Lhokseumawe, dan variabel permintaan berpengaruh secara positif dan signifikan terhadap pendapatan pedagang ikan tongkol lisong di Kota Lhokseumawe. Secara simultan (uji F) variabel modal dan permintaan berpengaruh positif dan signifikan terhadap pendapatan pedagang ikan tongkol lisong di Kota Lhokseumawe.

2. Nilai $\mathrm{R}^{2}$ pada penelitian ini sebesar 0.815245 . Nilai tersebut merupakan proporsi semua variabel bebas dalam menjelaskan pendapatan pedagang ikan tongkol lisong di Kota Lhokseumawe tahun 2018 yaitu sebesar 81.5245 persen. Sedangkan sisanya adalah sebesar 0.184755 atau 18.4755 persen dijelaskan oleh variabel lain yang tidak termasuk didalam model penelitian.

\section{Saran}

Berdasarkan hasil penelitian di atas, maka rekomendasi saran dari penulis adalah sebagai berikut: 
1. Bagi pemerintah Kota Lhokseumawe disarankan agar lebih memperhatikan fasilitas penunjang pelayanan pasar seperti WC umum, musholla, tempat pembuangan sampah dan saluran pembuangan air yang baik sehingga menjadi pasar yang bersih dan nyaman baik bagi pembeli maupun bagi pedagang itu sendiri. Dan diharapkan pemerintah dapat memberikan pinjaman modal dari lembaga keuangan khususnya bagi para pedagang ikan tongkol lisong.

2. Bagi pedagang ikan tongkol lisong disarankan agar memperbesar modal usaha karena modal memberikan pengaruh yang positif terhadap peningkatan pendapatan. Dan diharapkan pedagang ikan tongkol lisong dapat mencatat antara pemasukan yang diterima dan biayabiaya yang harus dikeluarkan selama berdagang sehingga para pedagang ikan tongkol lisong dapat mengontrol lebih rinci pengeluaran maupun pendapatan yang diterima.

\section{DAFTAR PUSTAKA}

Antara,I.K.A. dan Aswitari,L.P. 2016. Beberapa Faktor Yang Mempengaruhi Pedagang Kaki Lima Di Kecamatan Denpasar Barat. E-Jurnal EP Unud. Volume 5 Nomor 11. Halaman 1265-1291.

Artaman,D.M.A. Yuliarmi,N.N. dan Djayastra,I.K.

2015. Analisis Faktor-Faktor Yang Mempengaruhi Pedagang Pasar Seni Sukawati Gianyar.E-Jurnal EP Unud. Volume 2 Nomor 4. Halaman 87-105.

Daniel, Moehar. 2002. Pengantar Ekonomi

Pertanian. Jakarta: PT Bumi Aksara.

Ekonomi. 2017. Jenis-Jenis Permintaan.

Http://Ilmu.Ekonomi.ac.id(Di Akses 05 November 2017).

Fauzi, Ahmad. 2004. Ekonomi Sumber Daya Alam Dan Lingkungan Teori dan Aplikasi. Jakarta: PT Gramedia Pustaka Utama.

Fitria,Noor Aini. 2014. Analisis Faktor-Faktor Yang Mempengaruhi Pendapatan Pedagang Tape Singkong Di Kota Probolinggo (Studi Kasus Pedagang
Tape Singkong Di Jln. Soekarno Hatta, Kelurahan Ketapang, Kecamatan Kademangan, Kota Probolinggo).Portal Garuda. Halaman 1-11.

Http://Repository.Widyatama.ac.id (Di Akses 05 November 2017).

Jamal, B. 2014. Analisis Faktor-Faktor Yang Mempengaruhi pendapatan Nelayan (Studi Nelayan Pesisir Desa Klampis Kecamatan Klampis Kabupaten Bangkalan). Portal Garuda. Halaman 119.

Kompas. 2017. Perkembangan Sektor Perikanan Bikin Surprise. Http://Jakarta.Kompas.com(Di Akses 01 November 2017).

Kurniawan, Paulus. Budhi, Made Kembar Sri. 2015. Pengantar Ekonomi Mikro Dan Makro. Yogyakarta: CV Andi Offset.

Lamia, Karof Alfentino. 2013. Faktor-Faktor Yang Mempengaruhi Tingkat Pendapatan Nelayan Kecamatan Tumpaan, Kabupaten Minahasa Selatan. Issn. Vvolume 1 Nomor 4. Halaman 1748-1759.

Mayoli, O.P. 2017. Pengaruh Modal, Tenaga Kerja, Pengalaman, Jarak Tempuh dan Umur Terhadap Pendapatan Nelayan di Kecamatan Lengayang Kabupaten Pesisir Selatan. Portal Garuda. Halaman $1-10$

Patty, F.N. dan Rita, M.R. 2015. Faktor-Faktor Yang Mempengaruhi Pendapatan Pedagang Kaki Lima (Studi Empiris Pkl Di Sepanjang Jln . Jenderal Sudirman Salatiga). Issn. Volume 2 Nomor 4. Halaman 87-105.

Riyanto, Bambang. 2007. Dasar-Dasar Pembelanjaan perusahaan Edisi Keempat. Yogyakarta: BPFE.

Ridha, A. dan Putri, S. 2017. Faktor-Faktor Yang Mempengaruhi Pendapatan Usaha Kerajinan Tas Aceh di Desa Ulee Madon Kecamatan Muara Batu Kabupaten Aceh Utara. Jurnal Samudra Ekonomika. Volume 1 Nomor 1. Halaman 87-93. 
Setiawan. Kusrini, Dwi Endah. 2010.

Ekonometrika.Yogyakarta: CV Andi Offset.

Soeharno. 2009. Teori Mikro Ekonomi. Yogyakarta: CV Andi Offset.

Sugiyono. 2015. Statistika Untuk Penelitian. Bandung: Alfabeta.

Sukirno, Sadono. 2013. Mikro Ekonomi Teori Pengantar Edisi Ketiga. Jakarta: PT Raja Grafindo Persada.

Sumardianto, Yulinda, E. dan Bathara, L. 2016. Faktor Yang Mempengaruhi Pendapatan Pedagang Pengecer Ikan Laut Segar Di Pasar Terapung Tembilahan Kabupaten Indragiri Hilir Provinsi Riau. Portal Garuda. Halaman 113.

Teguh, Muhammad. 2010. Ekonomi Industri. Jakarta: PT Raja Grafindo Persada.

Trisnawati, M. Rosa, Y. Del, dan Putri, Y. E. 2013. Pengaruh Modal Kerja, Tenaga Kerja, Jam Kerja, Terhadap Pendapatan Nelayan Tradisional Di Nagari Koto Taratak Kecamatan Sutera Kabupaten Pesisir Selatan. Portal Garuda. Halaman 1-16. 